\title{
ON THE INTRIGUING STRANDING OF FOUR CUVIER'S BEAKED WHALES, ZIPHIUS CAVIROSTRIS G. CUVIER, 1823, ON THE LESSER ANTILLEAN ISLAND OF BONAIRE
}

\author{
by \\ PETER J. H. VAN BREE \\ Institute of Taxonomic Zoology, University of Amsterdam, The Netherlands \\ $\&$ \\ INGVAR KRISTENSEN \\ Caribbean Marine Biological Institute, Curaçao, Netherlands Antilles
}

\begin{abstract}
The stranding of four Cuvier's Beaked Whales, Ziphius cavirostris, on the Lesser Antillean Island of Bonaire on April 3, 1974 is reported. The death of the animals was most probably caused by some kind of underwater explosion.
\end{abstract}

On April 3, 1974, the bloated and already decomposed bodies of four large dolphins were washed ashore on the northern coast (Playa Grandi) of the Lesser Antillean Island of Bonaire $\left(12^{\circ} 17^{\prime} \mathrm{N}, 68^{\circ} 20^{\prime} \mathrm{W}\right)$, off the coast of Venezuela. The stranding of these animals, more than 4 meters long, drew great attention; photographs of the dolphins were taken (e.g. figs. $1 \& 2$ ) and a notice concerning them appeared in the local press. After a few days on the rocky beach, the bodies of the dolphins were towed far out to sea, apparently for reasons of sanitation and the stench. The ease and/or the indifference, with which the local authorities disposed of important biological material, seemed rather curious.

The first problem which posed itself was that of the zoological identification of the dolphins. Thanks to the kind cooperation of Messrs. L. D. Gerharts, Father A. P. Swartjes, H. Linkels, C. Noome and J. A. van Duren we were able to study a number of black and white photographs and colour slides that had been made of the specimens. On first sight it was clear that they were Beaked Whales, Ziphioidea ${ }^{1}$ ). Furthermore it was clear from the photographs that the animals had a single pair of teeth located at the apex of the mandible (see fig. 3). Among the Northern Atlantic Beaked Whales, only three species show this character. viz. Hyperoodon ampullatus, Ziphius cavirostris and Mesoplodon mirus. In view of the shape of the teeth, well developed and bulbous (see Moore, 1968: 234, 241), and by the evidence of the distribution of the three species mentioned (Moore \& Wood, 1957; Moore, 1966), we came to the conclusion that the Bonaire dolphins belonged to the species Ziphius cavirostris G. Cuvier, 1823. Such an identification is not surprising as the species is known to occur in the Caribbean (for a stranding on the nearby situated Island of Curaçao, see van Bree et al., 1973).

Assuming the identification to be correct, the question as to how four specimens could be stranded together (a mass stranding) forced itself upon us, as in Beaked Whales mass strandings occur only rarely. For a long time scientists and laymen have looked for the cause or causes of mass strandings and many theories have been put forward, e.g. suicide, contagious disease and heavy infection with internal parasites. However, to us the most plausible theory is that put forward by Gilmore (1959) and Dudok van Heel (1962). In this theory three factors, acting alone or in com-

1) For this superfamily the first author has previously used the name Hyperoodontoidea Gray, 1866, thereby following Moore, 1968 (: 276). It appears, however, that the diagnosis of the family Ziphiidae, or superfamily Ziphioidea, by Gray, 1865 (: 528 ) is not only older but also valid. 


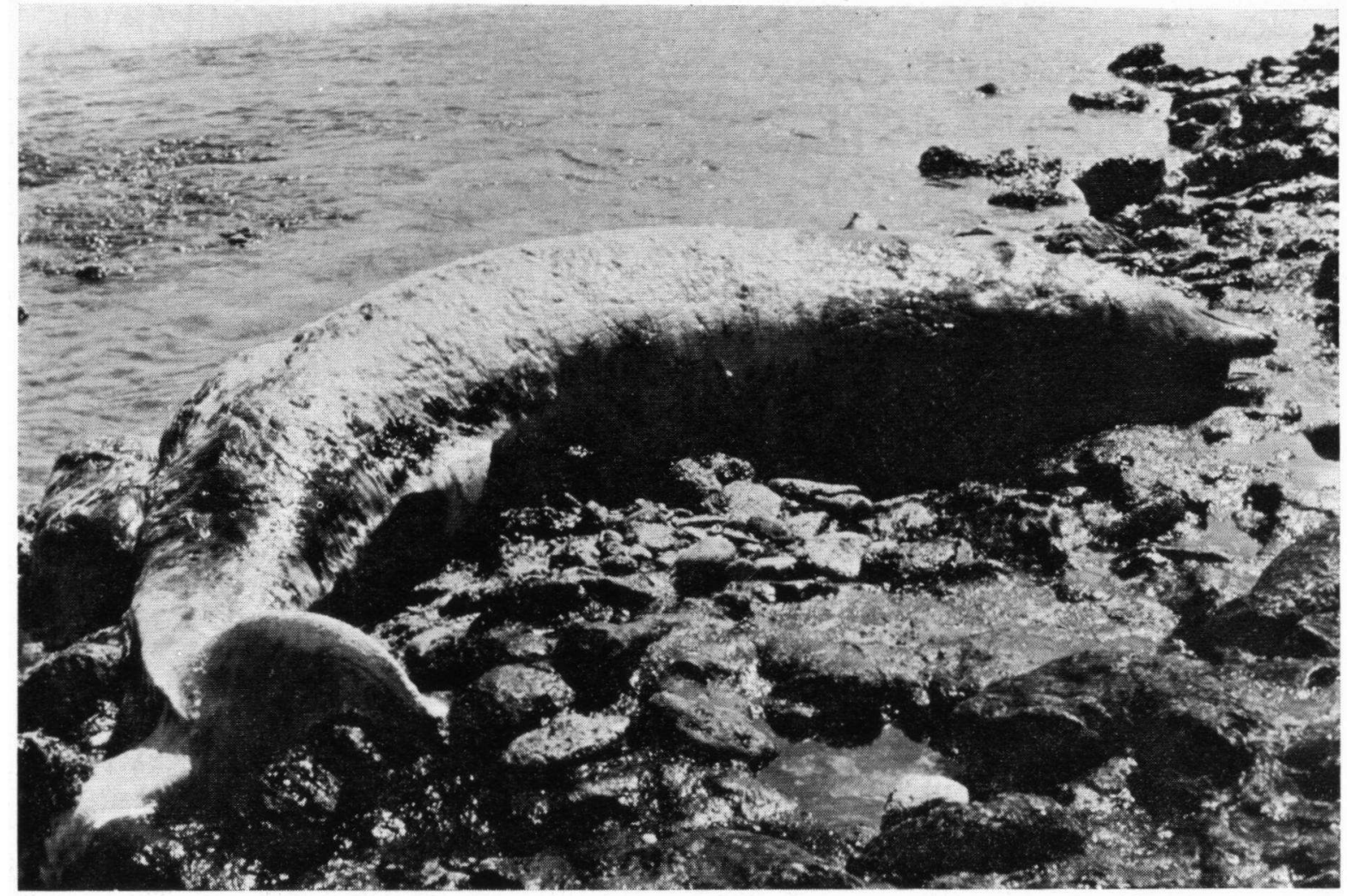

Fig. 1. One of the four Cuvier's Beaked Whales washed ashore on the Island of Bonaire on April 3, 1974. After a colour slide made by $C$. Noome.

bination, may cause mass strandings, viz. (1) failure to receive early warning due to misleading information from their sonar system, (2) the possession of a sensitive nervous system which may produce panic and an irrational response to the misleading sonar information, (3) non-adaptation to shallow water of a pelagic species of cetaceans with a strong social cohesion (see also Robson \& van Bree, 1971).

Dudok van Heel (1962: 476-483) compiled a list of mass strandings and in a large number of these he produced very strong evidence that the abovementioned factors were the cause of stranding. Studying Dudok van Heel's list of mass strandings (mass strandings defined here as strandings of three or more specimens) one may come to the conclusion that no mass strandings have been recorded among the Mysticeti and that among the Odontoceti there neither have been mass strandings of the Monodontoidea nor of the Platanistoidea, whilst among the Physeteroidea they are well known in Physeter macrocephalus, the Sperm Whale. Among the Ziphioidea they are rare, as will be discussed further on. They are well known among the Delphinoidea, being almost a diagnostic character of the Globicephalidae ${ }^{2}$ ) [Orcinus orca, Globicephala melaena, Globicephala macrorhynchus, Pseudorca crassidens, Feresa attenuata, Orcaella brevirostris (probably not occurring in this coastal species), and Peponocephala electra], and exceptional in the other representatives of this taxon (Lagenorhynchus acutus, Grampus griseus (?), and Steno bredanensis).

As previously stated, mass strandings occur very rarely among the Beaked Whales. Dudok van Heel (loc. cit.) lists only two cases, viz. the stranding of about 25 specimens of Mesoplodon grayi on Waitangi Beach, Chatham Islands, in 1875 (von Haast, 1876) and of four specimens of Hyperoodon ampullatus at Brora (Sutherland), Great Britain, on September 20, 1927 (Fraser, 1934). Details concerning the circumstances of these strandings are unfortunately unknown. No mass strandings have been recorded of Ziphius cavirostris, though recurrent strandings on the same locality may occur

2) The author of this family is not Gill, 1872, as stated by van Bree \& Cadenat (1968: 200), but Gray, 1866 (: 62). 




Fig. 2. Another specimen of Ziphius cavirostris from the stranding on the Island of Bonaire. After a colour slide made by $C$. Noome.



(Mitchell, 1958). We therefore found the stranding of four specimens of Cuvier's Dolphin rather puzzling, although we realized that it may not have been a stranding in the proper sense of the word. Washed ashore or stranded, the problem remained of how the four specimens died together.

On May 5, 1964, three specimens of Lagenorhynchus albirostris (Gray, 1846) were found dead on the beach of the Netherlands' North Sea Island of Texel; a fourth specimen, almost certainly belonging to the same school as the first three dolphins, was found drifting at sea 16 days later (van Bree \& Nijssen, 1964). Also in explaining this mass stranding in a species of which no previous mass strandings were known, we had difficulties. After submitting the typescript of the article by van Bree \& Nijssen it came to our notice that just

Fig. 3. Anteriormost part of the head of one of the four Beaked Whales washed ashore on the Island of Bonaire. Note the rather large and bulbous teeth. After a colour slide made by $C$. Noome. 
prior to the date on which the White-beaked Dolphins were found, the Netherlands' Navy had experimented with new anti-submarine depthcharges off the coast of Texel. We tried to get official confirmation of these experiments but we did not succeed, probably due to security restrictions.

We were informed that prior to the stranding of the four Cuvier's Beaked Whales on Bonaire, near the island Navy manoeuvres took place. We, of course, suspected that the dolphins accidentally had become the victims of some kind of underwater explosion related to the manoeuvres. We inquired at the local Navy staff on Curaçao whether our supposition was correct but we did not get a confirmative answer. Two days before the stranding of the dolphins, however, inhabitants of Bonaire heard a heavy explosion off the coast in the neighbourhood of a naval vessel of unknown nationality. As we have been informed, the vessel was dumping ammunition which caused the underwater explosion.

It therefore is very tempting to believe - if not certain - that the Cuvier's Beaked Whales on Bonaire, like the White-beaked Dolphins on Texel, died accidentally through human interference. If so, we have to take in account the possibility that this type of accidents occurs in other strandings or mass strandings of Cetacea as well. It is also conceivable that naval operations in general could interfere with the biology of the larger species of whale.

\section{REFERENCES}

Bree, P. J. H. van \& J. CAdenat, 1968. On a skull of Peponocephala electra (Gray, 1846) (Cetacea, Globicephalinae) from Sénégal. Beaufortia, 14 (177) : 193-202.

Bree, P. J. H. van, F. Creutzberg \& I. Kristensen, 1973. On strandings of Cuvier's Whale, Ziphius cavirostris G. Cuvier, 1823, on the Lesser Antillean Islands of Sint Maarten and Curaçao. Lutra, 15 (1/3) : 6-8, $1 \mathrm{pl}$.

Bree, P. J. H. Van \& H. NiJssen, 1964. On three specimens of Lagenorhynchus albirostris (Gray, 1846) (Mammalia, Cetacea). Beaufortia, 11 (139) : 85-93.

Dudok van Heel, W. H., 1962. Sound and Cetacea. Neth. J. Sea Res., 1 (4) : 407-508.

Fraser, F. C., 1934. Report on Cetacea stranded on the British coasts from 1927 to 1932: 1-41, 6 maps (Trustees Brit. Mus., London).

Gilmore, R. M., 1959. On the mass strandings of Sperm Whales. Pacif. Nat., 1 (9/10) : 9-16.

GraY, J. E., 1865. Notices of a new genus of delphinoid whales from the Cape of Good Hope, and of other cetaceans from the same seas. Proc. zool. Soc. London, 1865 : $522-529$.

,- 1866 . Catalogue of Seals and Whales in the British
Museum (2nd ed.) : i-vii, 1-402 (Trustees Brit. Mus., London).

Hanst, J. Von, 1876. On a new ziphioid whale. Proc. zool. Soc. London, 1876 : 7-13.

Mitchell, E. D., 1968. Northeast Pacific stranding distribution and seasonality of Cuvier's beaked whale Ziphius cavirostris. Can. J. Zool., $46: 265-279$.

MoORE, J. C., 1966. Diagnoses and distributions of Beaked Whales of the genus Mesoplodon known from North American waters. In : K. S. NorRIS ed., Whales, Dolphins and Porpoises : $32-61$ (Univ. California Press, Berkeley \& Los Angeles).

-, 1968. Relationships among the living genera of Beaked Whales, with classifications, diagnoses and keys. Fieldiana Zool., 53 (4) : I-IV, 209-298.

MoORE, J. C. \& F. G. WoOD, 1957. Differences between the Beaked Whales Mesoplodon mirus and Mesoplodon gervaisi. Am. Mus. Novit., 1831: 1-25.

RobSON, F. D. \& P. J. H. VAN BREE, 1971. Some remarks on a mass stranding of Sperm Whales, Physeter macrocephalus Linnaeus, 1758, near Gisborne, New Zealand, on March 18, 1970. Z. Säugetierk., 36 (1) : $55-60$. 